\title{
Electrical Nondestructive Determination of Collision Fatigue Limit for PZT
}

\author{
Yoshitake Nishi, Ryosuke Kondoh, Kunio Yamada and Hayato Irisawa \\ Department of Materials Science, Tokai University, Hiratsuka 259-1292, Japan
}

To determine the collision fatigue limit for piezoelectric ceramics, an electrical nondestructive method was suggested. The materials show large changes in electrical potential induced by pressure on the collision. Measurements on this type of material found a relationship between the maximum value of electrical potential $\left(V_{\mathrm{m}}\right)$ and supplied collision energy $\left(E_{\mathrm{c}} \mathrm{s}\right)$ below the collision fatigue limit. It was expressed by the following simple equation.

$$
V_{\mathrm{m}}=9.5\left(E_{\mathrm{c}}^{\mathrm{s}}\right)^{0.5}
$$

Applying the critical differential electrical potential $\left(V_{\mathrm{c}}=4 \mathrm{~V}\right)$, we confirmed that the collision fatigue limit was nondestructively determined for PZT materials.

(Received October 20, 2003; Accepted January 9, 2004)

Keywords: nondestructive, fatigue life, collision, fatigue limit, piezoelectric (PZT)

\section{Introduction}

Vibration, which is mainly induced by space debris crush and other human oriented accidents, is a serious problem in space ship. Piezoelectric effects are useful to control the vibration in space. On the other hand, collision fracture and fatigue fracture are serious problems to apply material systems and structures, such as supersonic generator, energy absorber and electrical power generator. Thus, it is important to know the collision fracture toughness, its fatigue life and its fatigue limit of the materials. However the fatigue test is usually quite time consuming. Therefore, a determination test, precisely obtained the collision fatigue limit, has been expected. If a nondestructive method of collision fatigue limit can be developed, it should be applied broadly in the fields of aerospace, civil, mechanical, electronic, and biomedical engineering, as well as in emerging technologies.

A piezoelectric effect is characterized by a generation of electrical potential induced by pressure, and is often found for polarized ceramics and organic materials. Based on the piezoelectric effect, a new original method can be developed to determine the impact fatigue limit. In the present work, a determination method is investigated for piezoelectric ceramics, which generate a large change in electrical potential induced by pressure. ${ }^{1-5)}$

Piezoelectric ceramics have become increasingly important as dampers, sensors and actuators used in the emerging technology of intelligent material systems and structures. Generation of electric potential has been clearly observed by collision for piezoelectric ceramics. The maximum value of electrical potential $\left(V_{\mathrm{m}}\right)$ is controlled by dynamic energy, which is indicated by the supplied collision energy $\left(E_{\mathrm{c}}{ }^{\mathrm{s}}\right){ }^{6)} \mathrm{In}$ the present work, a $V_{\mathrm{m}}-E_{\mathrm{c}}{ }^{\mathrm{s}}$ relationship has been determined for PZT piezoelectric ceramics. Furthermore, using the observed $V_{\mathrm{m}}-E_{\mathrm{c}}$ s relationship, we have tried to confirm that the collision fatigue limit is precisely estimated via an electrical determination method.

\section{Experimental}

To obtain reproducible results of fracture test, PZT samples, commercially used as a flint produced by TOKAI CORPORATION with high quality control, were prepared by sintering under high pressure. The chemical composition and structural changes of PZT samples were precisely confirmed by means of EDS (energy dispersive X-ray spectrometer, HORIBA EMAX-5770W) and X-ray diffraction, respectively. The metal atomic fractions were 0.55 for lead, 0.24 for zirconium and 0.21 for titanium. The physical properties of PZT samples were 381 for Vickers' hardness, $113 \mathrm{MPa}$ for bending fracture stress, $3.00 \mathrm{MNm}^{-3 / 2}$ for $K_{1 \mathrm{C}}$ value and $7.60 \mathrm{~g} / \mathrm{cm}^{3}$ for PZT sample density. The fatigue test, as

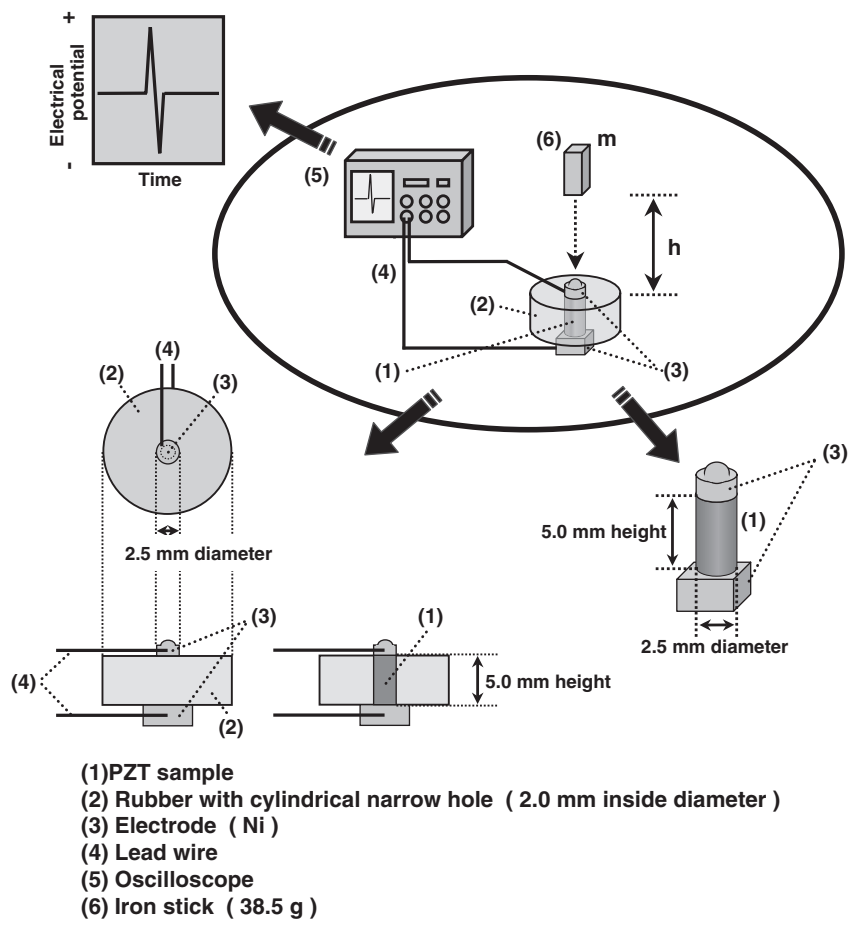

Fig. 1 Schematic diagram of collision test of PZT sample rapped with rubber sheet. 


\section{Before fracture}

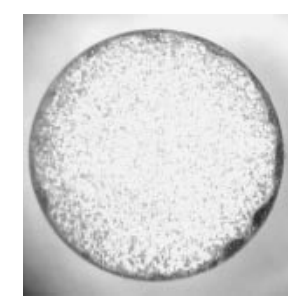

\section{After fracture}

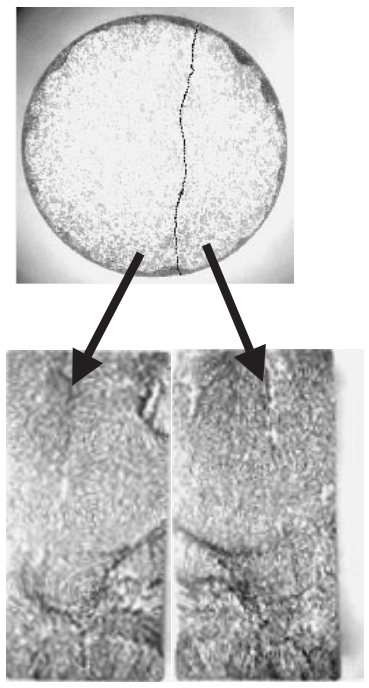

Fig. 2 Optical Micrograph of PZT surface before and after fracture crack origin just below surface and crack propagation were observed.

shown in Fig. 1, was repeatedly performed by iron stick $(38.5 \mathrm{~g})$ collision against the PZT sample $(5 \mathrm{~mm}$ height, $2.5 \mathrm{~mm}$ diameter) rapped with rubber sheet, until the sample was apparently fractured by optical observation, as shown in Fig. 2. The supplied collision energy $\left(E_{\mathrm{c}} \mathrm{s}\right)$ was equal to static energy, which was determined by sample mass, gravity acceleration speed and the height $(h)$ from the sample top surface to the iron stick bottom. The maximum value of electrical potential $\left(V_{\mathrm{m}}\right)$ at collision was measured by means of an oscilloscope, as shown in Fig. 1. The crack was observed using a scanning electron microscopy (SEM) and optical profile projection.

\section{Results and Discussion}

\subsection{Collision fatigue limit}

The fatigue test is repeatedly performed by iron stick collision against the five PZT samples at different collision energies, until the samples are apparently fractured by optical observation, as shown in Fig. 2. When $N_{\mathrm{f}}$ and $N_{\mathrm{t}}$ are fractured and total numbers of PZT samples at different collision energiesqbthe fracture ratio $\left(R_{\mathrm{f}}\right)$ is expressed by a following equation.

$$
R_{\mathrm{f}}=N_{\mathrm{f}} / N_{\mathrm{t}}
$$

Figure 3 shows the change in fracture ratio $\left(R_{\mathrm{f}}\right)$ against number $\left(N_{\mathrm{c}}\right)$ of collision at different supplied collision energies $\left(E_{\mathrm{c}} \mathrm{s}: \mathrm{mJ}\right)$. The fracture ratio was always 1.0 above $1325 \mathrm{~mJ}$ of $E_{\mathrm{c}} \mathrm{s}$. The large collision energy above $1325 \mathrm{~mJ}$ fractured the PZT sample at one time collision. The collision number enhanced the fracture ratio $\left(R_{\mathrm{f}}\right)$ at the collision energies from 19.0 to $994 \mathrm{~mJ}$. On the other hand, the fracture

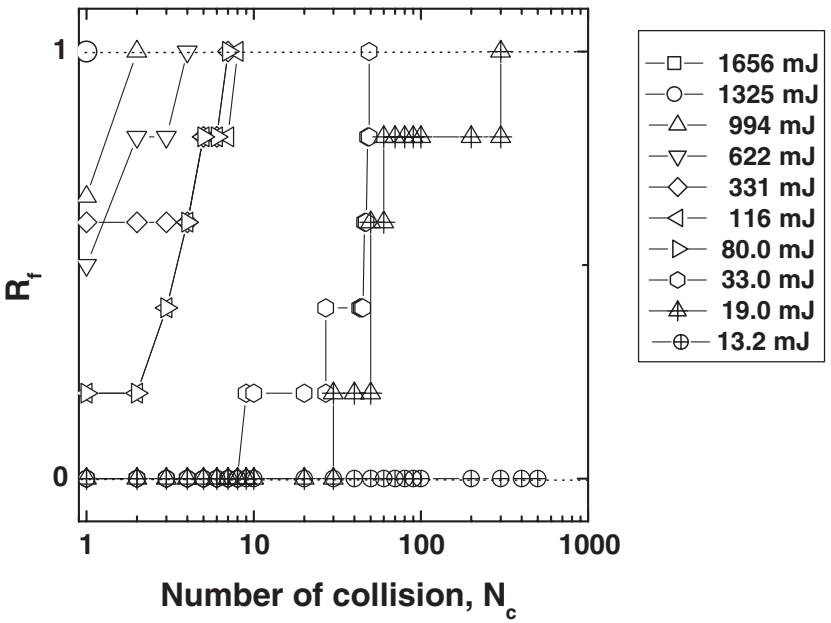

Fig. 3 Change in fracture ratio $\left(R_{\mathrm{f}}\right)$ of PZT cylindrical sample rapped with rubber sheet against total number of collision $\left(N_{\mathrm{c}}\right)$ at different supplied collision energies $\left(E_{\mathrm{c}}{ }^{\mathrm{s}}: \mathrm{mJ}\right)$.

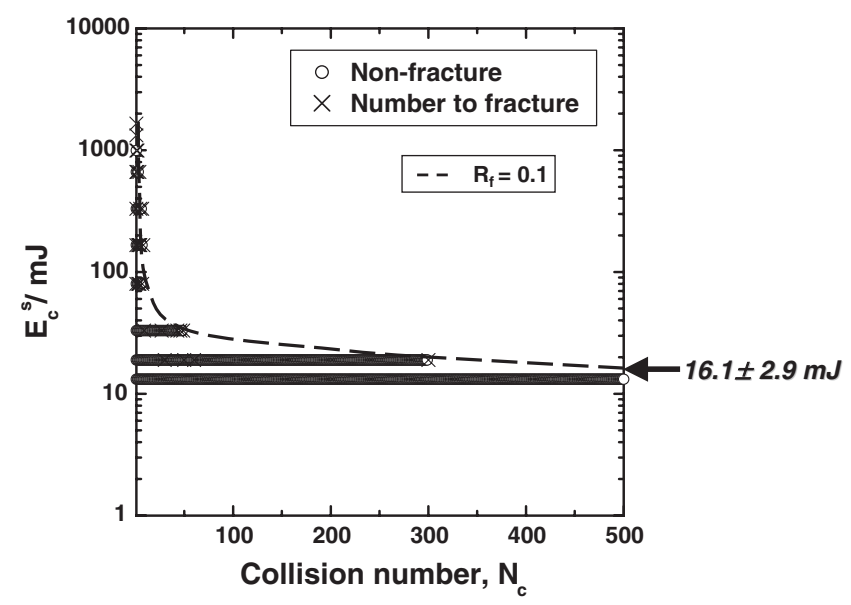

Fig. 4 Change in supplied collision energy $\left(E_{\mathrm{c}}^{\mathrm{s}}\right)$ against collision number $\left(N_{\mathrm{c}}\right)$ of PZT cylindrical sample rapped with rubber sheet.

ratio was always zero below $13.2 \mathrm{~mJ}$ of $E_{\mathrm{c}}{ }^{\mathrm{s}}$. Namely, the PZT sample rapped with rubber sheet wasn't fractured by the small collision energy below $13.2 \mathrm{~mJ}$.

Figure 4 shows the change in supplied collision energy $\left(E_{\mathrm{c}} \mathrm{s}: \mathrm{mJ}\right)$ against number $\left(N_{\mathrm{c}}\right)$ of collision. If the fracture ratio $\left(R_{\mathrm{f}}\right)$ was 1.0, the collision fracture always occurred for samples examined at one time. The relationship between $N_{\mathrm{c}}$ and $E_{\mathrm{c}}$ s from $1325 \mathrm{~mJ}$ to $16.1+/-2.9 \mathrm{~mJ}$ was obtained. When the collision energy was smaller, the total number of collision of the fracture became large. On the other hand, the collision fatigue limit was determined for the PZT piezoelectric ceramics, as shown in Fig. 4 . When the $E_{\mathrm{c}}{ }^{\mathrm{s}}$ was below $13.2 \mathrm{~mJ}$, the collision fracture could not be observed by the collision test. The fracture ratio $\left(R_{\mathrm{f}}\right)$ is always zero below the fatigue limit. Micro-cracks cannot be observed below the collision fatigue limit by SEM observation. Thus, we defined the collision fatigue limit as $16.1+/-2.9 \mathrm{~mJ}$ for the PZT sample. The long lifetime on collision fatigue of the material lies below the limit, as shown in Fig. 4. 


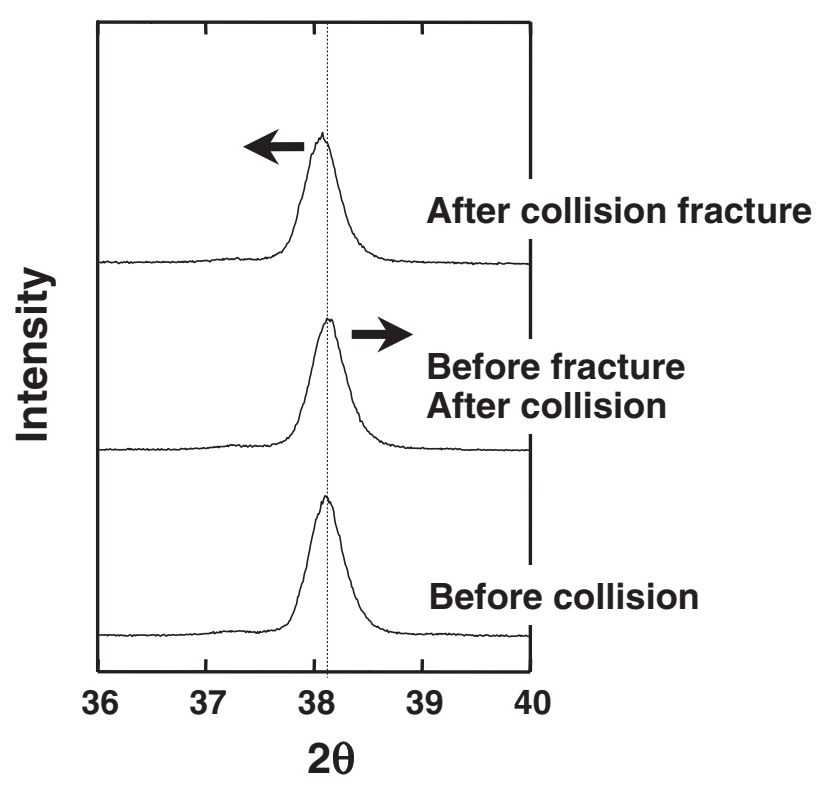

Fig. $5 \mathrm{Cu}-\mathrm{K} \alpha \mathrm{X}$-ray diffraction patterns of PZT (111) crystal plane.

\subsection{Structure change by collision}

The change in electrical potential versus time under collision stress was observed. In the region above the collision fatigue limit, the residual strain was stored up to the point of fatigue fracture. Figure 5 shows the X-ray diffraction peak for the (111) crystal plane of PZT samples before and after collision testing above the collision fatigue limit. The collision increased the peak angle and then decreased the crystal plane distance before the fracture, whereas the collision decreased the peak angle and increased the lattice plane distance after the fracture. Based on the results, the collision generally enhanced the compressive stress before the fracture time and relaxed the stored stress of the crystal lattice structures at the fracture time. The irreversible stored strain probably generated the crack, which induced the fracture above the limit. On the other hand, the change in the (111) crystal plane distance could not be detected below the collision fatigue limit because of the reversible elastic strain.

\subsection{Determination method of collision fatigue limit}

Generation of electrical potential had been clearly observed by collision for the piezoelectric ceramics. The maximum value of electrical potential $\left(V_{\mathrm{m}}\right)$ (see Fig. 1) was controlled by dynamic energy. It was dominated by the supplied collision energy $\left(E_{\mathrm{c}}^{\mathrm{s}}\right)$. The electrical energy was proportional to the mechanical energy. ${ }^{6-8)}$ The electrical energy $(W)$ was correlated to electrical potential $(V)$ and electrical resistivity $(R)$, as a following equation.

$$
W=V^{2} / R
$$

A relationship was expected between the maximum value of electrical potential $\left(V_{\mathrm{m}}\right)$ (see Fig. 1) and supplied collision energy $\left(E_{\mathrm{c}}{ }^{\mathrm{s}}\right)$ below the collision fatigue limit (see Fig. 4). The relationship (see solid line in Fig. 6) was expressed by a following simple equation.

$$
V_{\mathrm{m}}=A\left(E_{\mathrm{c}}^{\mathrm{s}}\right)^{n}
$$

\section{Collision fatigue limit}

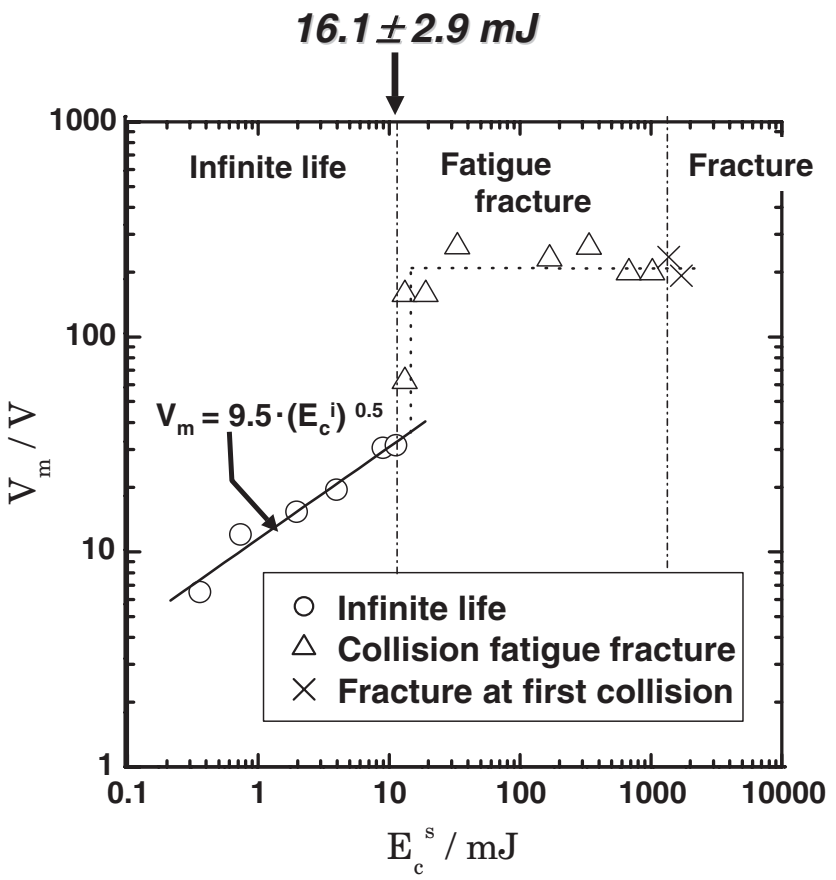

Fig. 6 Relationship between the maximum value of electrical potential $\left(V_{\mathrm{m}}\right)$ and supplied collision energy $\left(E_{\mathrm{c}}{ }^{\mathrm{s}}\right)$ rapped with rubber sheet.

Here $A$ and $n$ were constants. Figure 6 shows relationship between the maximum value of electrical potential $\left(V_{\mathrm{m}}\right)$ and supplied collision energy $\left(E_{\mathrm{c}}^{\mathrm{s}}\right)$. If the collision energy was perfectly equal to the kinetic energy just before the collision, the $n$ value should be 0.5 . Based on the relationship between electrical potential $\left(V_{\mathrm{m}}\right)$ and supplied collision energy $\left(E_{\mathrm{c}}{ }^{\mathrm{s}}\right)$, the constant A was 9.5 (see Fig. 6). It was experimentally obtained below the collision fatigue limit. The differences between supplied and experimental values were mainly caused by collision energy loss.

When the collision energy exceeded the collision fatigue limit, the maximum value of electrical potential deviated severely from the $V_{\mathrm{m}}-E_{\mathrm{c}}{ }^{\mathrm{s}}$ relationship. Namely, it was difficult to reproduce the maximum value of electrical potential $\left(V_{\mathrm{m}}\right)$ value at certain supplied collision energy $\left(E_{\mathrm{c}}{ }^{\mathrm{s}}\right)$ above the collision fatigue limit. The large $V_{\mathrm{m}}$ deviation from the $V_{\mathrm{m}}-E_{\mathrm{c}}{ }^{\mathrm{s}}$ relationship was induced by the stress relaxation of micro-crack and micro-twin generation.

A relationship held between the maximum values of electrical potential and supplied collision energy below the collision fatigue limit. On the other hand, the electrical potential showed a large deviation from the obtained relationship at larger collision energies above the limit. Using this observed deviation, the collision fatigue limit could be precisely and conveniently determined. Figure 7 shows relationship between differential electrical potential $\left(\Delta V_{\mathrm{m}}=\left|V_{\mathrm{m}}-V_{\mathrm{m}}{ }^{\mathrm{R}}\right|\right)$ and supplied collision energy $\left(E_{\mathrm{c}}^{\mathrm{s}}\right)$. Large $\Delta V_{\mathrm{m}}$ value could be found above the limit. The critical differential electrical potential $\left(\Delta V_{\mathrm{c}}=5 \mathrm{~V}\right)$ was defined to determine the collision fatigue limit. Figure 8 shows relationship between reduced number $\left(R_{\mathrm{n}}\right)$ of non-deviated sample and supplied collision energy $\left(E_{\mathrm{c}} \mathrm{s}\right)$. Here the reduced number of non-deviated sample $\left(R_{\mathrm{n}}=N_{\mathrm{n}} / N_{\mathrm{t}}\right)$ was number of 
Collision fatigue limit with compressive stress

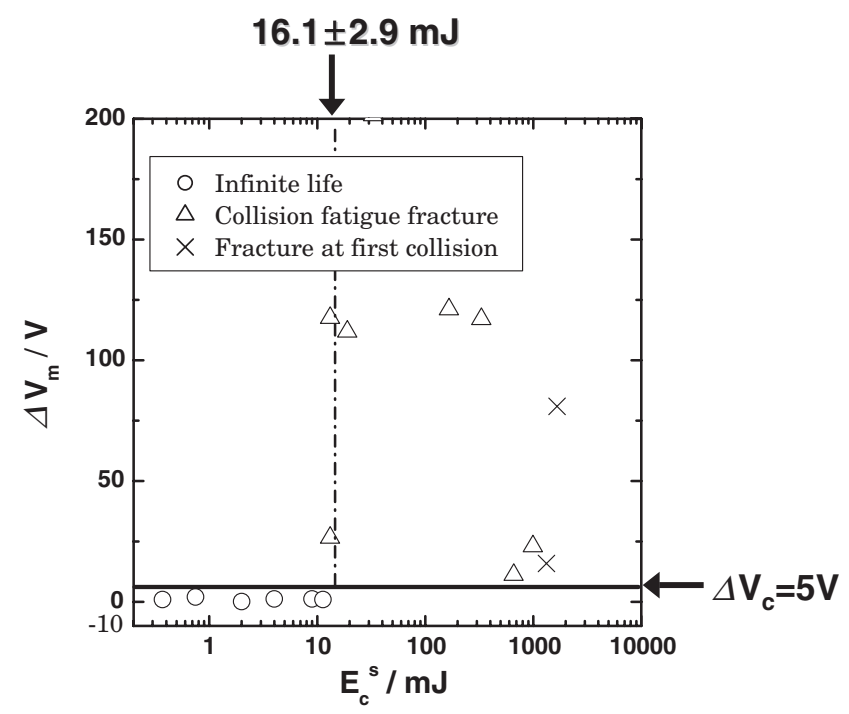

Fig. 7 Relationship between differential electrical potential $\left(\Delta V_{\mathrm{m}}\right)$ and supplied collision energy $\left(E_{\mathrm{c}}{ }^{\mathrm{s}}\right)$ of PZT sample rapped with rubber sheet. Here, $\Delta V_{\mathrm{c}}$ in a critical differential electrical potential at collision fatigue limit.

non-deviated samples $\left(N_{\mathrm{n}}\right)$ per total number of samples $\left(N_{\mathrm{t}}\right)$. The $R$ values were 1.0 below the collision fatigue limit, whereas the $R$ values are far below 0.1 above the collision fatigue limit. The critical rate of non-deviated sample $\left(R_{\mathrm{c}}\right)$ was defined to be 0.1 . If collision test with electrical power generation was performed, the collision fatigue limit could be determined. Therefore, the electrical nondestructive method could develop for piezoelectric ceramics. Evaluating the collision fatigue limit in this way appears to be a new method.

\section{Conclusions}

In summary, we have shown that a nondestructive method to determine the collision fatigue limit can be applied to PZT piezoelectric ceramics. When the collision energy was small (below the collision fatigue limit), a relationship held between electrical potential and supplied collision energy. On the other hand, at larger collision energies (above the limit), the electrical potential showed a large deviation from the obtained relationship. Using this observed deviation, a collision fatigue limit could be determined. The critical differential electrical potential $\left(\Delta V_{\mathrm{c}}=-5 \mathrm{~V}\right)$ at collision fatigue limit was suggested. Evaluating the collision fatigue limit in this way appears to be a new method. The method held the promise of yielding the information precisely,

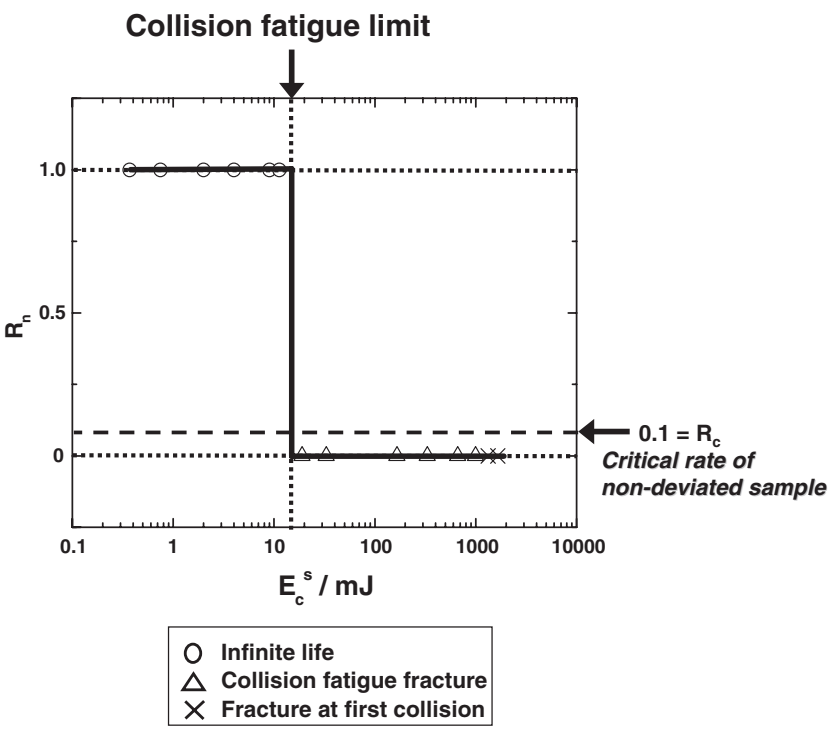

Fig. 8 Relationship between reduced number $\left(R_{\mathrm{n}}\right)$ of PZT sample rapped with rubber sheet and supplied collision energy $\left(E_{\mathrm{c}}^{\mathrm{s}}\right)$.

conveniently and non-destructively. If electrical power generation induced by pressure could be found for other materials, the nondestructive method of collision fatigue limit could be applied broadly for supersonic generator, damper and electrical power generator in the fields of aerospace, civil, mechanical, electronic, and biomedical engineering, as well as in emerging technologies.

\section{Acknowledgements}

Authors would like to thank TOKAI CORPORATION for their useful to prepare PZT.

\section{REFERENCES}

1) Y. Kawamura, N. Matsumoto, H. Kamataki and K. Mukae: Jpn. J. Appl. Phys. Suppl. 28 (1989) 77-79.

2) R. E. Newnham, Q. C. Xu, S. Kumar and L. E. Cross: J. Wave-Material Interaction. 4 (1989) 3-10.

3) R. E. Newnham and G. R. Ruschau: J. Am. Ceram. Soc. 74 (1991) 463480.

4) D. Berlincourt: J. Acoust. Soc. Am. 91 (1992) 3034-3040.

5) S. Egusa and N. Iwasawa: J. Appl. Phys. 78 (1995) 6060-6070.

6) C. Garabedian, P. Gonnard and H. Ohanessian: J. Phys. III. FRA. 3 (1993) 1603-1615.

7) T. Ikeda: Atsudenzairyougaku no kiso, (in Japanese: Basic Technology of Pezo-materials, Ohmu Pub. Co., Tokyo, 1984) pp. 1-4.

8) T. Shiozaki: Atsudenzairyou no seizou to ouyou, The chaper I, (in Japanese: Production and application of Pezo-materials, CMC Pub.Co., Tokyo. 1984). 